\title{
Testing and Evaluation of Language Skills
}

\author{
${ }^{1}$ Chen Desheng, ${ }^{2}$ Ashitha Varghese, \\ 1. Ph.D. Scholar, Department t of English and Foreign Languages, Bharathiar University, Coimbatore- \\ 641046. \\ 2. Ph.D. Scholar, Department t of English and Foreign Languages, Bharathiar University, Coimbatore- \\ 641046.
}

\begin{abstract}
Testing and evaluation of language skills and competencies are very important components of language teaching. Testing becomes an integral part of teaching because it provides significant information or inputs about the growth and achievement of learner's difficulties, styles of learning, anxiety levels. Effective teaching and effective testing are two sides of the same coin. A curriculum is what constitutes a total teachinglearning programme composed of overall aims, syllabuses, materials, methods and testing in short. It provides a framework of knowledge and capabilities, selected to be appropriate to a particular level. Test evaluates not only the progress and achievement of learners but also the effectiveness of the teaching materials and methods used.
\end{abstract}

Keywords: Evaluation, Evaluand, Language, Skill, Test

\section{Introduction}

Language test broadly classified into two types as testing skills and testing knowledge of content. Skills such as listening, speaking, reading, and writing and sub- skills such as comprehension, vocabulary, grammar, spelling, punctuation, etc. Deferent kinds of tests are there to test student's knowledge in language, the tests like non-referential test, aptitude test, proficiency test, achievement test and diagnostic test.

\section{Discussion about Testing}

Within the last three decades there have been tremendous theoretical and methodological developments within the field of evaluation. Despite its progress, there are still many fundamental problems faced by this field as "unlike medicine, evaluation is not a discipline that has been developed by practicing professionals over thousands of years, so we are not yet at the stage where we have huge encyclopedias that will walk us through any evaluation step-by-step", or provide a clear definition of what evaluation entails (Davidson, 2005). It could therefore be argued that a key problem that evaluators face is the lack of a clear definition of evaluation, which may "underline why program evaluation is periodically called into question as an original process, whose primary function is the production of legitimate and justified judgments which serve as the bases for relevant recommendations.". However, the strict adherence to a set of methodological assumptions may make the field of evaluation more acceptable to a mainstream audience but this adherence will work towards preventing evaluators from developing new strategies for dealing with the myriad problems that programs face.

It is claimed that only a minority of evaluation reports are used by the evaluand (client) (Datta, 2006). One justification of this is that "when evaluation findings are challenged or utilization has failed, it was because stakeholders and clients found the inferences weak or the warrants unconvincing" (Fournier and Smith, 1993). Some reasons for this situation may be the failure of the evaluator to establish a set of shared aims with the evaluand, or creating overly ambitious aims, as well as failing to compromise and incorporate the cultural differences of individuals and programs within the evaluation aims and process.

None of these problems are due to a lack of a definition of evaluation but are rather due to evaluators attempting to impose predisposed notions and definitions of evaluations on clients. The central reason for the poor utilization of evaluations is arguably due to the lack of tailoring of evaluations to suit the needs of the client, due to a predefined idea (or definition) of what an evaluation is rather than what the client needs are (House, 1980).

\section{Definition of Evaluation}

Evaluation is the comparison of actual (project) impacts against the agreed strategic plans. It looks at the original objectives, at what was accomplished, and how it was accomplished. It can be formative that is taking place during the life of a project or organisation, with the intention of improving the strategy or way of functioning of the project or organisation. It can also be summative, drawing learnings from a completed project or an organisation that is no longer functioning. 
Evaluation is inherently a theoretically informed approach (whether explicitly or not), and consequently a definition of evaluation would have be tailored to the theory, approach, needs, purpose and methodology of the evaluation itself. Having said this, evaluation has been defined as:

- A systematic, rigorous, and meticulous application of scientific methods to assess the design, implementation, improvement or outcomes of a program. It is a resource-intensive process, frequently requiring resources, such as, evaluator expertise, labour, time and a sizeable budget

- 'The critical assessment, in as objective a manner as possible, of the degree to which a service or its component parts fulfils stated goals' (St Leger and Walsworth-Bell). The focus of this definition is on attaining objective knowledge, and scientifically or quantitatively measuring predetermined and external concepts.

- 'A study designed to assist some audience to assess an object's merit and worth' (Shufflebeam). In this definition the focus is on facts as well as value laden judgements of the programs outcomes and worth.

\section{Purpose of Evaluation}

The main purpose of a program evaluation can be to "determine the quality of a program by formulating a judgment" Stake and Schwandt (2006).

An alternative view is that "projects, evaluators and other stakeholders (including funders) will all have potentially different ideas about how best to evaluate a project since each may have a different definition of 'merit'. The core of the problem is thus about defining what is of value."From this perspective, evaluation "is a contested term", as "evaluators" use the term evaluation to describe an assessment, or investigation of a program whilst others simply understand evaluation as being synonymous with applied research.

Not all evaluations serve the same purpose some evaluations serve a monitoring function rather than focusing solely on measurable program outcomes or evaluation findings and a full list of types of evaluations would be difficult to compile. This is because evaluation is not part of a unified theoretical framework, drawing on a number of disciplines, which include management and organisational theory, policy analysis, education, sociology, social anthropology, and social change.

\section{Standards in Testing and Evaluation}

Depending on the topic of interest, there are professional groups which look to the quality and rigor of the evaluation process.

The Joint Committee on Standards for Educational Evaluation has developed standards for program, personnel, and student evaluation. The Joint Committee standards are broken into four sections: Utility, Feasibility, Propriety, and Accuracy. Various European institutions have also prepared their own standards, more or less related to those produced by the Joint Committee. They provide guidelines about basing value judgments on systematic inquiry, evaluator competence and integrity, respect for people, and regard for the general and public welfare.

The American Evaluation Association has created a set of Guiding Principles for evaluators. The order of these principles does not imply priority among them; priority will vary by situation and evaluator role. The principles run as follows:

\section{Testing Language skills}

$>$ Listening

$>$ Speaking

$>$ Reading

$>$ Writing

\section{Types of Language Tests}

\section{Achievement test}

- $\quad$ associated with process of instruction

- $\quad$ assesses where progress has been made

- $\quad$ should support the teaching to which it relates

- Alternative Assessment

- need for assessment to be integrated with the goals of the curriculum

- learners are engaged in self-assessment

\section{Proficiency test}

- aims to establish a test taker's readiness for a particular communicative role

- general measure of "language ability" 
- measures a relatively stable trait

- used to make predictions about future language performance (Hamp-Lyons, 1998)

\section{Some ways of describing tests}

- high-stakes test

Objective

Indirect

Discrete-point

Aptitude

Proficiency

External

Norm-Referenced

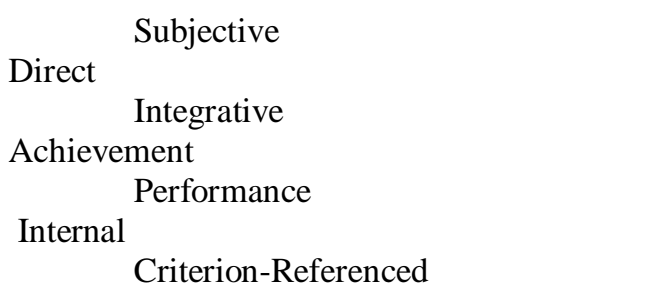

\section{Evaluating language skills}

Evaluating the usefulness of a language test

\section{Essential measurement qualities \\ $>$ reliability \\ $>$ construct validity}

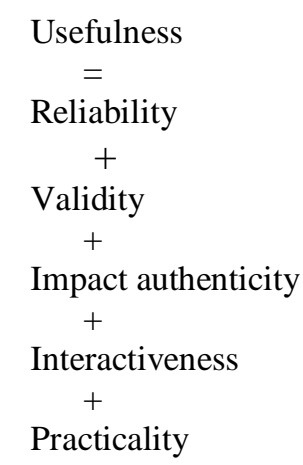

\section{Conclusion}

Testing and evaluation takes major role in language teaching and learning. We can conduct different kinds of test to know about the students skills in language. After test we will do the standard evaluation. It will show the performance level of students. In language skills evaluation we can find the students problems in learning. Then we can find out the remedy for that particular problem. Evaluation is a systematic gathering of information for purposes of making decisions. It is the collection, analysis and interpretation about any aspects of a programme of education and training as part of a recognized process of judging its effectiveness. Evaluation is defined as an attempt to understand what is going on to judge its worth and make decisions about it. One can add many more reasons for doing evaluation. It is not just for measuring students learning at the end of a course. Tests are useful in diagnosis, prediction, selection, grading, guidance, self- correction, etc. There is internal as well as external evaluation in most educational institutions.

\section{Reference}

[1]. Rossi, P.H. Lipsey, M.W., \& Freeman, H.E. (2004). Evaluation: A systematic approach (7th ed.)..

[2]. Reeve, J. Peerbhoy, D. (2007). "Evaluating the evaluation: Understanding the utility and limitations of evaluation as a tool for organizational learning". Health Education Journal

[3]. Hurteau, M.; Houle, S., \& Mongiat, S. (2009). "How Legitimate and Justified are Judgments in Program Evaluation?" Evaluation

[4]. Potter, C. (2006). "Psychology and the art of program evaluation". South African journal of psychology.

[5]. Joint Committee on Standards for Educational Evaluation

[6]. American Evaluation Association Guiding Principles for Evaluators

[7]. UNEG

[8]. DAC Network on Development Evaluation Home Page

[9]. House, E. R. (1978). Assumptions underlying evaluation models. Educational Researcher.

[10]. Stufflebeam, D. L., \& Webster, W. J. (1980). "An analysis of alternative approaches to evaluation". Educational Evaluation and Policy Analysis. 